\title{
Marmara Bölgesinde Afet Çalışmalarının Değerlendirilmesi II
}

\author{
${ }^{* 1,2}$ Cengiz İpek ${ }^{1,2}$ Mehmet Dikici ${ }^{1,3}$ İbrahim Pay ${ }^{1,3}$ İsmet Kandilli ${ }^{1,2}$ İsmail Topçu \\ ${ }^{1}$ Türk Kızılay, Ankara, Türkiye \\ ${ }^{2}$ Alanya Alaaddin Keykubat Üniversitesi, Alanya, Antalya, Türkiye \\ ${ }^{3}$ Kocaeli Üniversitesi, Kocaeli, Türkiye
}

\section{Özet:}

Marmara bölgesi deprem açısından çok kırılgan bir bölgedir. Ekonomik potansiyel yüksek olduğundan önem arz etmektedir. Yoğun nüfusuyla ve sanayinin bulunduğu bölge olduğundan daha fazla risk taşımaktadır. Bu nedenle 1999 Kocaeli ve Düzce depremlerinden sonra Marmara bölgesi için deprem hasarlarını azaltma çalışmaları yapılmaktadır. Sismoloji, erken uyarı sistemleri, CBS ve afet algısı çalışmaları yanında depremde iletişim, kentsel dönüşüm, deprem haritalarının yenilenmesi, yapısal olmayan elemanlar gibi çalı̧̧malar da yapılmıştır. Bölgedeki nüfusun hazırlıklı ve dirençli bir toplum olması önemli hale gelmiştir. Bu makalede Marmara bölgesi için son çeyrek asır yapılan çalışmalar değerlendirilmiştir. Ancak bu çalışmalarda elde edilen sonuçlara bakıldığında bölge için master bir çalışmanın hala yapılmaya ihtiyaç duyulduğu anlaşılmıştır.

Anahtar kelimeler: Marmara bölgesi, kentsel dönüşüm, depremde iletişim, deprem haritaları, yapısal olmayan elemanlar

\section{Evaluation of Disaster Studies in Marmara Region II}

\author{
${ }^{* 1,2}$ Cengiz Ipek ${ }^{1,2}$ Mehmet Dikici ${ }^{1,3}$ İbrahim Pay ${ }^{1,3}$ İsmet Kandilli ${ }^{1,2}$ İsmail Topçu \\ ${ }^{1}$ Turkish Red Crescent, Ankara, Turkey \\ ${ }^{2}$ Alanya Alaaddin Keykubat University, Alanya, Antalya, Turkey \\ ${ }^{3}$ Kocaeli University, Kocaeli, Turkey
}

\begin{abstract}
:
Marmara region is very vulnerable because of earthquake history. It is important that high economic potential of the region. Due to its dense population and industrial areas where located has more risks. For this reason, after the 1999 Kocaeli and Düzce earthquakes, efforts are being made to reduce earthquake damages for the region. Besides studies of Seismology, early warning systems, GIS and disaster perception such as earthquake communication, urban regeneration, earthquake maps studies, Non structural elements have also being done. It becomes very important issue to have preparedness level of region residents and resilient population. In this paper, the last quarter century studies about the issue on the region has been evaluated. However, the study results show that any master study in disaster case for the region has not been done yet.
\end{abstract}

Key words: Marmara region, urban regeneration, earthquake communication, earthquake maps, Non Structural elements

\section{Giriş}

Marmara bölgesi sahip olduğu yoğun nüfus ve sanayi alanları ile dünyanın en riskli alanlarından biridir. Belli sebeplerle en fazla göç alan, ekonomiye katkısı ile endüstri sektörünün

*Corresponding author: Address: Faculty of Engineering, Department of Civil Engineering Alanya Alaaddin Keykubat University, Antalya TURKEY. E-mail address: cengiz.ipek@alanya.edu.tr, Phone: +905323503011 
bulunduğu alanda katma değer üreten ve turizm açısından da en zengin bölgedir. Bölge sahip olduğu tarihi zenginliği, Asya'dan Avrupa'ya geçiş güzergâhında bulunması önem kazanmakla birlikte, geçmişteki tarihi depremselliği ve Kuzey Anadolu Fay Bölgesine (KAF) yakın olması Şek.1.'de görüldüğü gibi çok büyük önem arz etmektedir. Şek.2.'de görüldüğü üzere 2018 yılında yaklaşık 26 milyon nüfusu (ülke nüfusunun üçte biri) ile 11 ilden oluşan bölge sanayi kentleri(ülke sanayisinin \%60) ile İstanbul, Kocaeli, Sakarya ve Bursa öne çıkmaktadır.

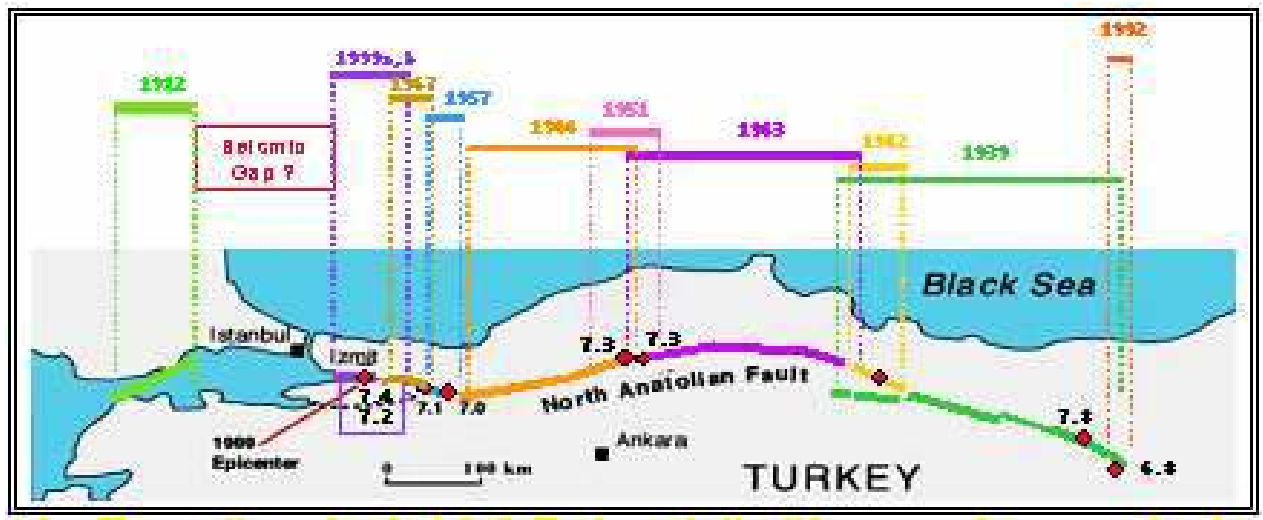

Şekil 1. 1939 dan beri NAFZ üzerindeki meydana gelen büyük depremler

1999 Kocaeli ve Düzce depremleri ile meydana gelen yaklaşık 19 bin can ve büyük ekonomik kayıp ile toplumun afetlere bakış algısı tamamen değişmiştir. Kurumlar ve özel sektör deprem afetinden sonra kısmen önemli dersler çıkarmıştır. İhtiyaca cevap vermeyen deprem yönetmenliği 2007 'de güncellenmiş, 2009'da T.C. Başbakanlık Afet ve Acil Durum Yönetimi Başkanlığ 1 (AFAD) kurulmuştur. İstanbul ili için deprem master planı Japan Investment Cooperation Agency (JICA) sponsorluğunda 2003 yılında, 2005 yılında Kocaeli'nde zemin profilleri çıkarılmış, Sakarya ilinde de zemin çalışmaları tamamlanmıştır.

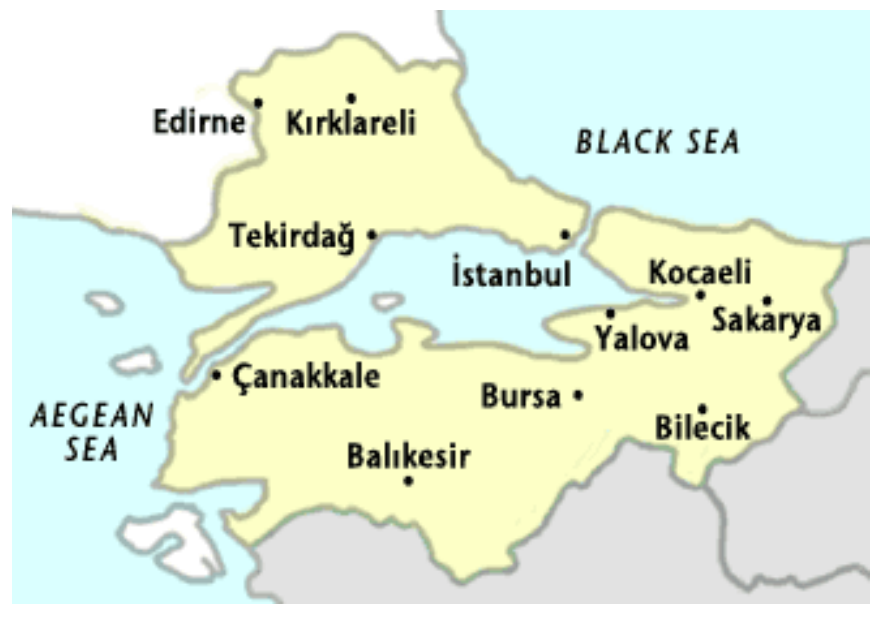

Şekil 2. Marmara bölgesi haritası, 2018

Sismoloji, deprem mühendisliği ve afet yönetimi konusunda akademik düzeyde birçok Kongre ve Sempozyum yapılmış, ulusal ve uluslararası çevrelerde hatırı sayılır çalışmalar 
yayınlanmıştır[1-29]. 2016 yılına kadar yerel düzeyde anılan 1999 deprem yıldönümleri ilk defa 2017 yılında Kocaeli ili Gölcük ilçesinde ve İstanbul'da ulusal düzeyde Türk Kızılayı ve AFAD katılımı sağlanarak, toplumun afet algısına vurgular yapılmıştır. Bu sebeple 2012/6306 sayılı yasa ile kentsel dönüşüm programı Gölcük’te başlatılması sağlanmıştır. Bu yıl itibari ile ülke genelinde yaklaşık 22,5 milyon yapı stokunun 7,5 milyonun kentsel dönüşüm ile 2035 'lere kadar yenilenmesi veya güçlendirilmesi Çevre ve Şehircilik Bakanlığı tarafından ifade edilmiştir. Dönüşüme muhtaç yapı stokunun yarısına yakını Marmara bölgesinde olması çarpıcı bir veridir. Yatak kapasitesinin 100 ve üzerindeki hastanelerin sismik izolatörle yapılmasının Sağlık Bakanlığınca tavsiye edilmesi (Göztepe Hastanesi, 1250 yataklı Kocaeli Şehir Hastanesi, Kocaeli Tıp Fakültesi vb.) 18.03.2018/30364(mükerrer) deprem yönetmenliği yayınlanması olumlu çalışma ve uygulamalardır. İnsani yardım kuruluş olarak kurulan 150 yıllık geçmişi olan Türk Kızılayı, Marmara bölgesinde olası müdahale için Marmara Afet Organize Merkezi (MAFOM) kurmuş ve kapasitesini artırmıştır. AFAD 'da Marmara bölgesinin her ilinde kapsamlı Türkiye Afet Müdahale Planı(TAMP) oluşturmuş ve kapasitesini artırmıştır. Bu kurum yılda en az 2 adet masa başı ve uygulama senaryoları hazırlamaktadır. Ayrıca Sağlık Bakanlığı bünyesinde afette etkin müdahale Ulusal Medikal Kurtarma Ekibi (UMKE) kurulmuş ve başarılı çalışmalar yapmaktadır. Bunun yanda MARDİM-Marmara Bölgesi'nde Deprem ve Zararlarının Azaltılması ve Türkiye'de Afet Eğitimi Projesi çalışması sonuçlanmıştır. Bu çalışma sonucunda Marmara bölgesinde her an 7 ve üzerinde bir büyüklükte depremin meydana gelebileceği ifade edilmiştir.

$\mathrm{Bu}$ çalışmada Marmara bölgesinde afet konusunda özellikle 1999 Kocaeli ve Düzce depremlerinden sonraki zamanda yapılan çalışmalar ele alınacaktır.

\section{Yapılan Çalışmalar}

Marmara bölgesinde afet konusunda Jeofizik mühendisliği ve sismoloji alanında, erken uyarı sistemleri, afette kullanılan iletişim sistemleri, toplumda afet bilinci geliştirilmesi konusunda kentsel dönüşüm (yeraltı ve yerüstü yapılar), afet yönetiminde Coğrafi Bilgi Sistemi (CBS) 'nin kullanılması çalışmalarının değerlendirilmesi yapılmıştır [26]. Özellikle afete müdahale uygulamalarında Türk Kızılay ve AFAD‘ın çalışmaları da öne çıkmaktadır. Bu makalede Kentsel dönüşüm, Depremde iletişim, Deprem haritaları ve Yapısal olmayan elemanlar konuları değerlendirilecektir.

\subsection{Kentsel dönüşüm çalışmaları}

Kentsel dönüşüm 19. Yüzyılda Avrupa'da başlamıştır. Türkiye'de 1950 lerde sanayi alanların ortaya çıkması ile birlikte köylerden kentlere büyük göçler sonucu düzensiz gecekondulaşma ve düzensizler şehirleşme meydana gelmiştir. $\mathrm{Bu}$ gün Marmara bölgesinde Kentsel dönüşüme ihtiyaç duyulan konut oran1 \%70'dir. Bu sorunun çözümü için 1966/775, 1984/ 2985, 2004/5104,2005/5393:5366 sırası ile yasalar çıkarılmıştır.

Gelecekte olası depremlerde yaşanabilecek can ve mal kaybını azaltmak amacıyla, 16.05.2012 tarihinde kabul edilen ve 31.05.2012 tarihinde Resmi Gazete yayınlanarak yürürlüğe giren 6306 sayılı Afet Riski Altındaki Alanların Dönüş̧ürülmesi Hakkında Kanun ilaveten 15.12.2012 tarihinde Resmi Gazete'de 6306 Sayılı Uygulama Yönetmeliği yürürlüğe girmiştir. 6306 sayılı kapsamında deprem etkisi altında Riskli Yapıların Tespit Edilmesine İlişkin Esaslar olarak Resmi 
Gazetede yayınlanmıştır. Yapıların risk tespitini daha hızlı yapılmasını hedefleyen ilkeler belirlenmiş ve Deprem yönetmenliğine uyulması zorunlu hale gelmiştir.

6306 sayılı kanunun etkin ve yaygın şekilde kullanımı amacıyla kat maliklerine ve kiracılara maddi kolaylıklar getirilmiştir. Ancak kentsel dönüşüme ihtiyaç duyulan bölgelerde en karlı alanlardaki dönüşümün hızlı bir şekilde gerçekleştirilirken, daha az karlı alanlarda nispeten daha yavaş, karsız veya gecekondu alanlarında ise dönüşüme uğramakta istenen düzeye ulaşmadığı ifade edilmektedir[27]. 17.08.2018 tarihi itibari ile 1 milyon 300 bin birimde kentsel dönüşüm proje çalışmaları devam etmektedir[29].

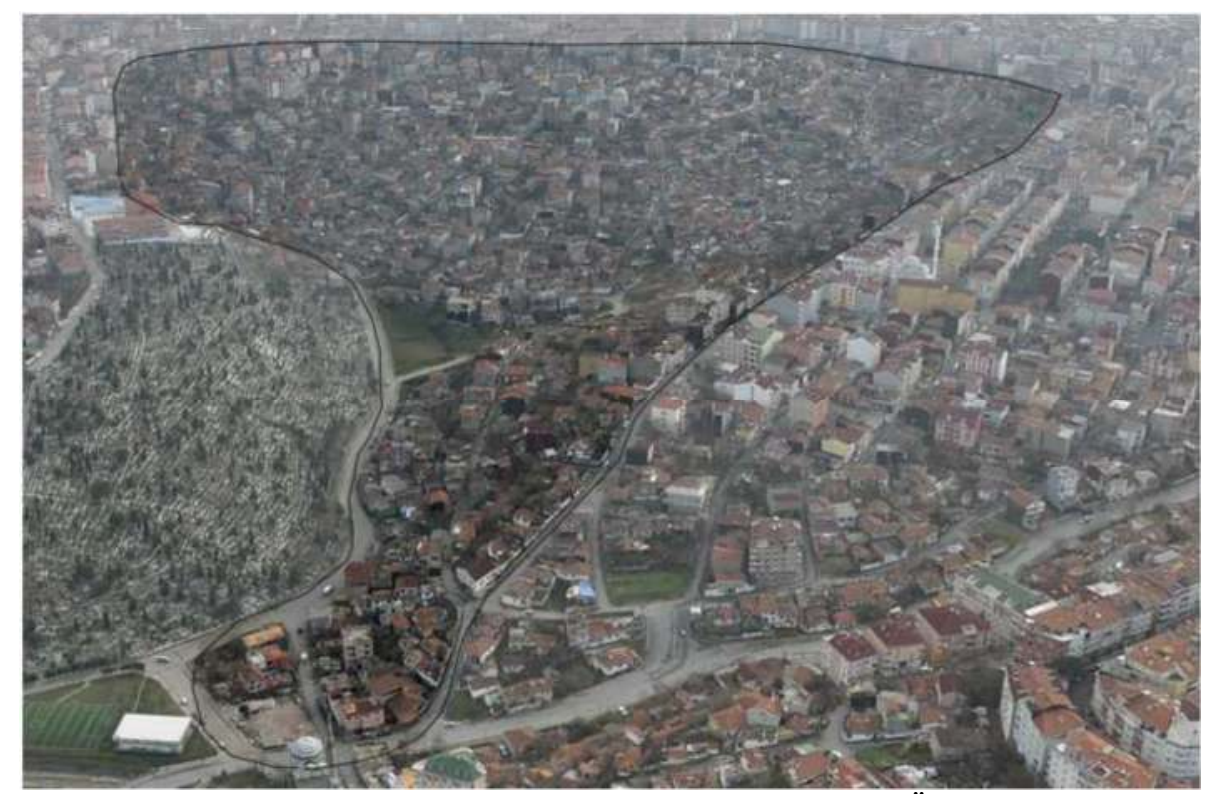

Şekil 3. Gaziosmanpaşa Sarıgöl - Yenidoğan Dönüşüm Öncesi[28].

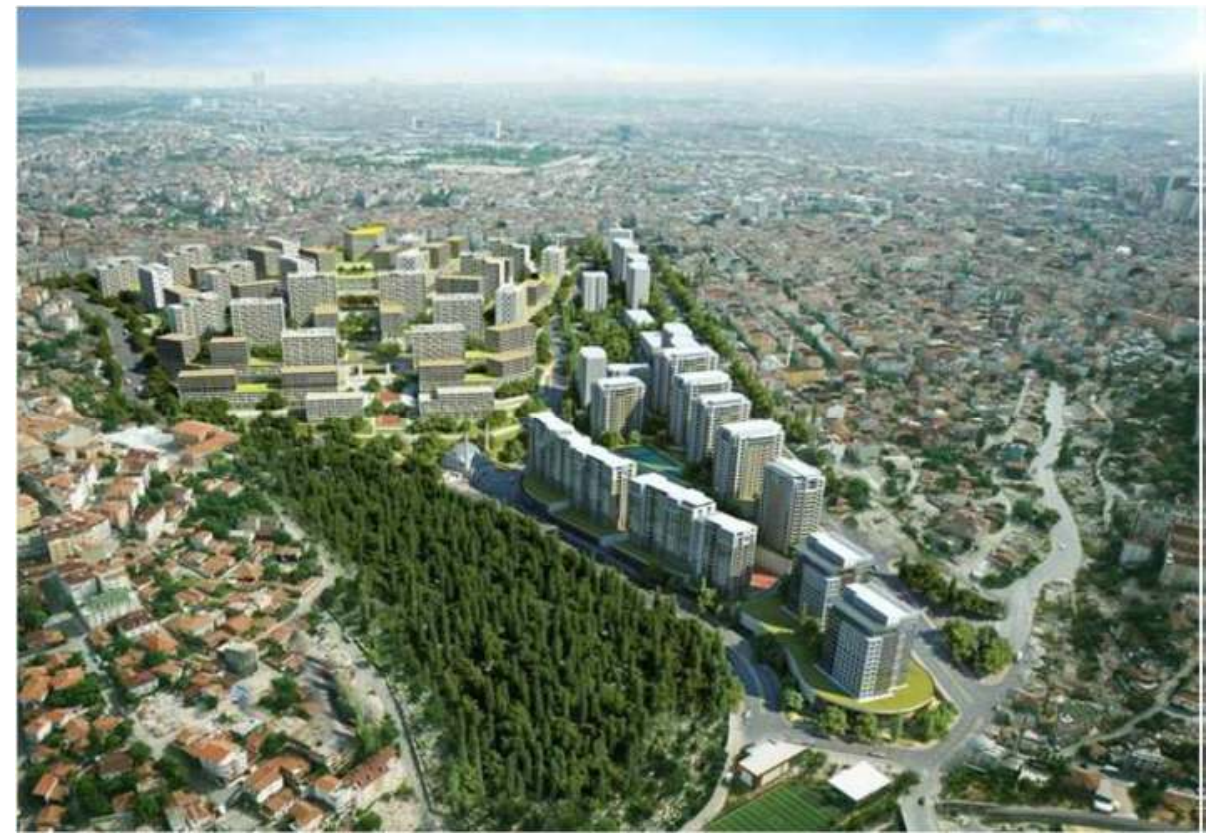


Şekil 4. Gaziosmanpaşa Sarıöl - Yenidoğan Dönüşüm Sonrası [28].

Şek.3 ve Şek.4 dönüşüm öncesi ve sonrası Gaziosmanpaşa ilçesindeki Kentsel dönüşüm projeleri göstermektedir. Şek.4 te Dönüşüm sonrası eğitim alanları \%58, yeşil alanları \%114, ibadet alanları \%83 park alanları \%382 artmıştır.

\subsection{Depremde iletişim}

Afet anında erişimin kolayı olması için Bilgi Teknolojilerin (BİT) kullanılması şarttır. Bununla alakalı dünyada İHAlar ve Mobil uygulamalar mevcuttur. Marmara bölgesinde afet sonrası durum tesbiti için anlık bilgi alınması gerekmektedir. Mobil Tabanlı Afet Yönetim sistemi kullanılarak afetlerden kaynaklanan riskleri azaltmak için, toplumun bütün kesimlerine iletişim kurulmalıdır. Sistem 'ihtiyaç listesi', "hasar tahmini", "yer arama", "kayıp kişi arama ve raporlama" ve "kaynak arama ve raporlama" modüllerinden oluşmaktadır. İzmirde afet uygulamasında kullanılan bu sistem Şekil 5'te Ana ekran ve Şekil 6 da"son depremler" ve "afet sırt çantası" araçlarının ayrıntılı ekran görüntülerini göstermektedir.

$\mathrm{Bu}$ uygulama ile deprem sonrası sağlıklı bilgi alınabilecek, zararlar minimize edilebilecek ve karar vericiler için hızlı erişilebilir, şeffaf bir ortam sağlayabilecektir.

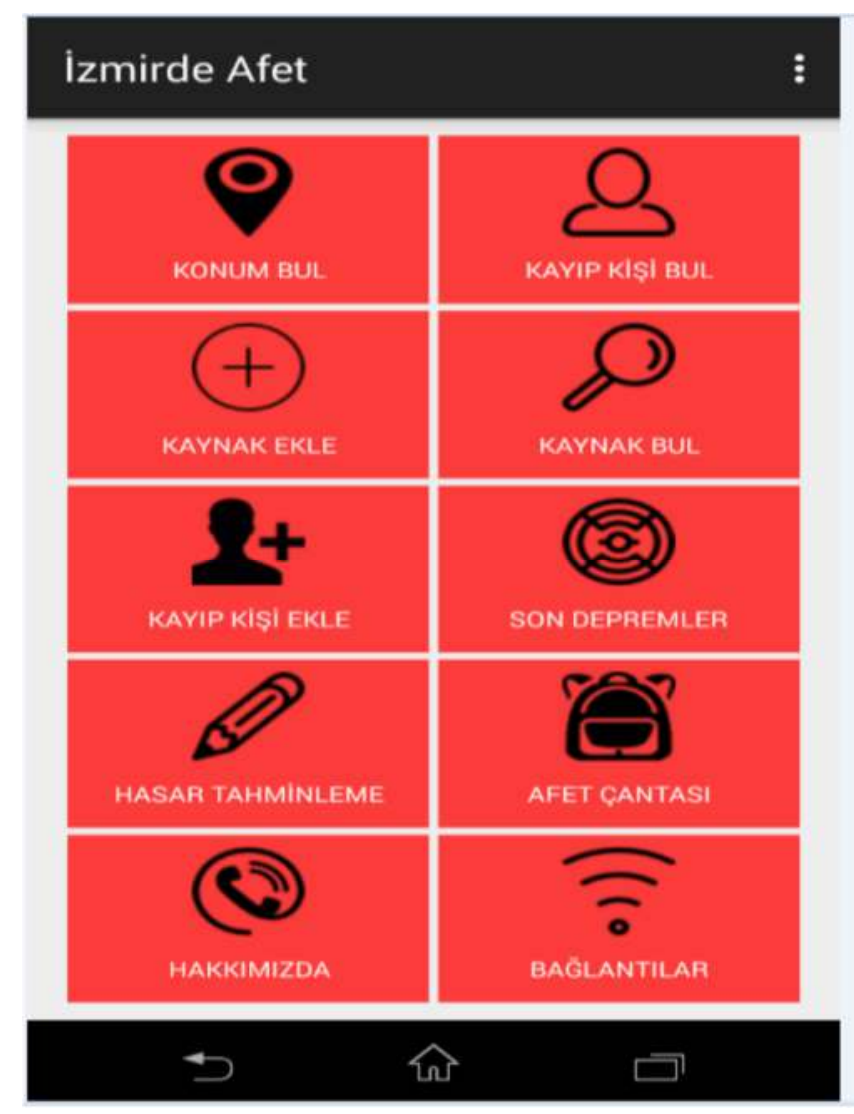


Şekil 5. Mobil Uygulama Ana Ekran [32].

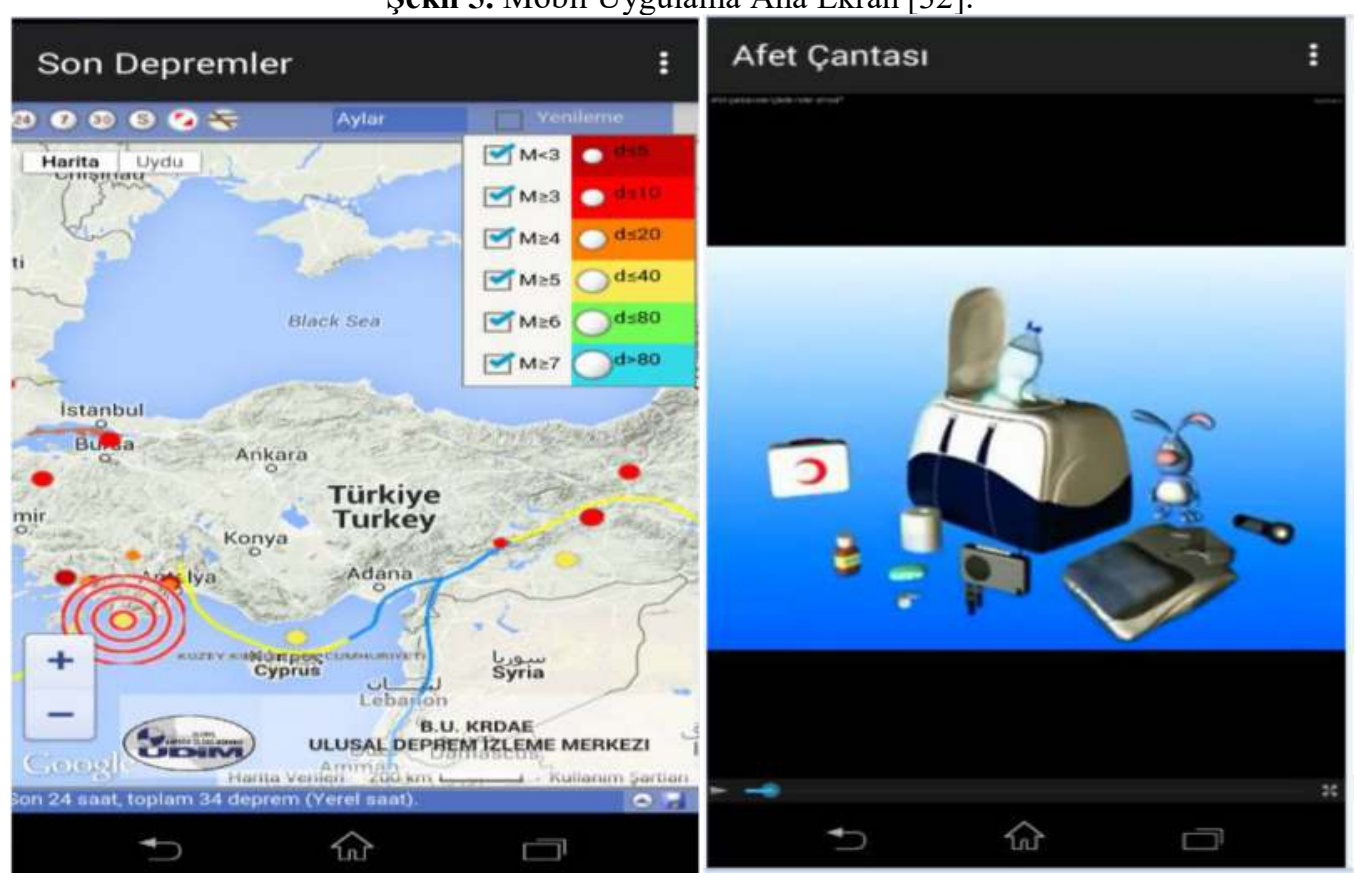

Şekil 6. Son Depremler ve Afet Çantası Modülleri [32].

16 Ağustos 2018 tarihinde Geleneksel olarak düzenlenen V. Uluslararası Deprem Gerçeği ve Kentleşme Çalıştayı, Afet Zararların Azaltılmasında Akıllı kent Uygulamaları Konulu pilot proje AFAD, Kocaeli Büyükşehir Belediyesi ve Gebze Teknik Üniversitesi arasında bir protokol ile imzalandı. Bu proje ile Afette bilişim teknolojileri kullanılarak bir altlık oluşturulacak ve bir izleme merkezinde takip edilebilecektir. Bu proje sonradan Ülkenin genelinde kullanılabilecektir.

\subsection{Deprem Haritalart}

Resmi Türkiye Deprem Bölgeleri Haritaları 1945, 1947, 1963, 1972 ve 1996 yıllarında olmak üzere beş kez değiştirilmiş̧ir. Deprem bölgeleri haritaları mühendislik sismolojisindeki gelişmeler, tektonik ve sismotektonik bulguların ve deprem kayıtlarının artması ile elde edilen yeni bilgi, yöntem ve verilerin 1 şığı altında geçmişte olduğu gibi gelecekte de zaman içinde değişecektir.

Başbakanlığa bağlı Afet ve Acil Durum Yönetimi Başkanlığı (AFAD) tarafından yeni bir Türkiye Deprem Bölgeleri haritası ve Türkiye Bina Deprem Yönetmeliği 18.03.2018/30364 (mükerrer) yayınlanmıştır. Ancak Deprem haritaları 01Ocak 2019 tarihinden itibaren yürürlüğe girecektir.

Deprem bölgeleri haritaları, yerleşim alanı için yer seçiminde, imar planlarının hazırlanması ve değiştirilmesinde, depreme dayanıklı yapıların projelendirilmesi ve hesaplamalarında gereksinim duyulan verileri sağlamak için, özellikle deprem nedeniyle oluşabilecek yer ivmelerini belirlemeye yönelik bilgiler vermesi bakımından deprem zararlarının azaltılması çalışmalarında önemli bir işlev üstlenmektedir[33]. 


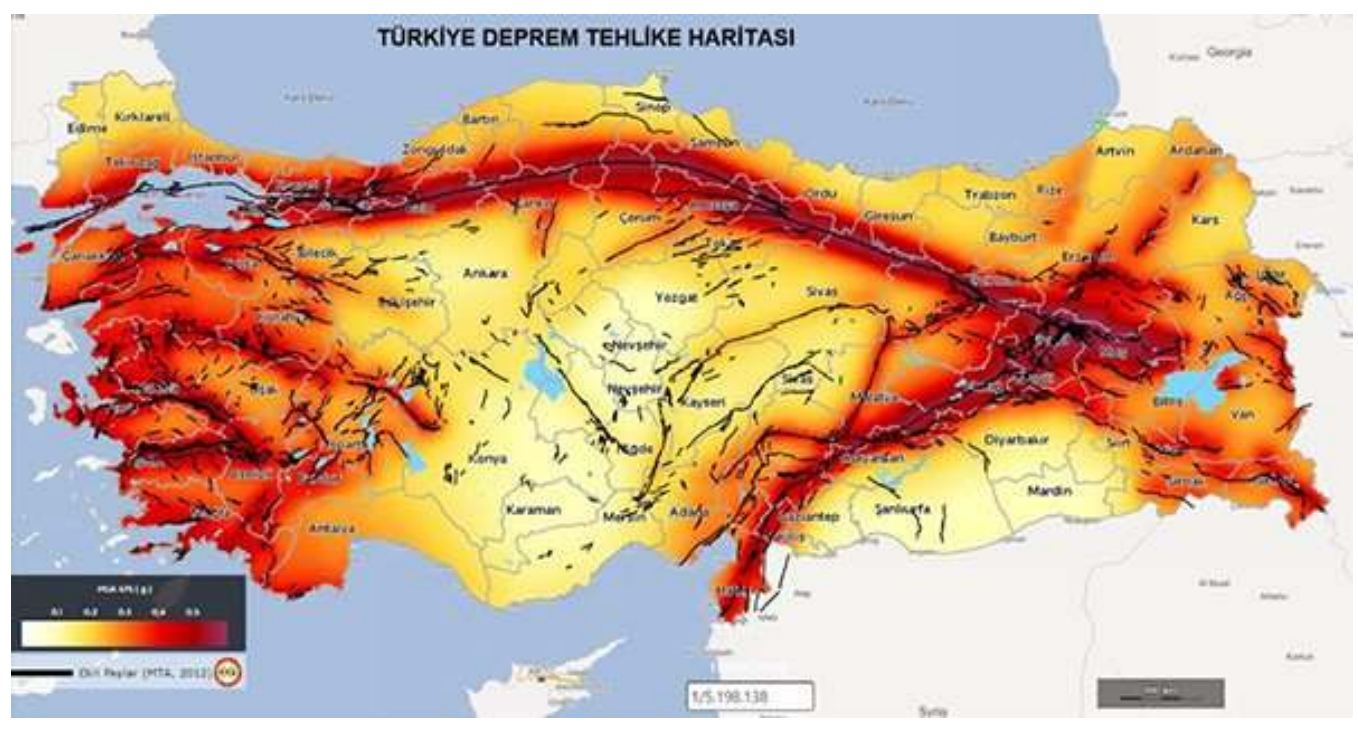

Şekil 7. Türkiye Deprem haritası (AFAD) 2018 [29,33].

Yeni deprem haritası deprem bölgelerine göre değil bölgelerde deprem kayıtları alınarak yapı tasarım için kullanılabilecektir.

\subsection{Yapisal olmayan Elemanlar}

Yapısal olmayan elemanlar yapısal elemanların dışındaki her türlü dış cephe kaplamaları, ayırıcı duvar ve bölmeler, çatılar, tavan ve yer kaplamaları, eşya ve mobilyalar, elektrik ve mekanik tesisat elemanları olarak tanımlanmaktadır.

1999 Kocaeli depremindeki yaralanmaların da \%50 si ve ölümlerin \%3'ü yapısal olmayan yapı elemanlarından kaynaklanmış, hayatta kalanların yaşadıkları maddi kayıpların \%30'unu mobilya, beyaz eşya, elektronik cihazların ve diğer değerli eşyaların oluşturduğu kanaatine varılmıştır Yapısal olmayan elemanlar; maliyet açısından yapı içindeki oranlamada farklı tespitler bulunmasına rağmen özellikle kritik ve ticari yapılarda bu oranın yüksek olduğu gözlenmiştir. Yapısal olmayan elemanlar, deprem afeti sonrası oluşabilecek hasarların; \%75-85 oranında olduğu tesbit edilmiştir[2,6,7].

Yapısal olmayan elemanlar, Tarihi müzeler, hastaneler, kütüphaneler ve otellerde önem kazanmaktadır. Depremden önce bunların uygun yapı elemanlarına tesbit edilmesi gerekmektedir.

Şekil 8' de 2006 da Hawaii Depremi sonrasıKona Hastanesi ameliyathanesinin yapısal olmayan eleman hasarı görülmektedir.

2018 yılında yayımlanan Deprem Yönetmenliğinde Yapısal olmayan elemanlar için bir bölüm ayrılmıştır. Ancak binadaki Yapısal olmayan elemanların kontrolu belediyelerce iskan izni sırasında denetlenmelidir. 


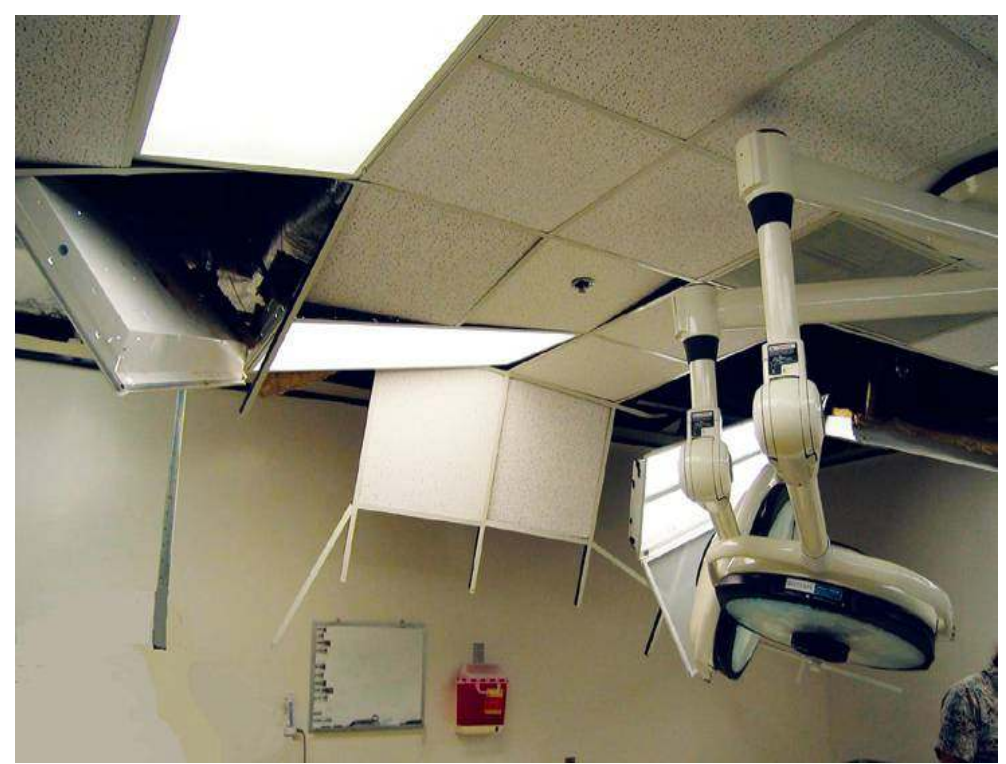

Şekil 8. Kona Hastanesi Hawaii Depremi 2006[2,5,7].

\section{Tartışma ve Öneriler}

Marmara bölgesinde afet üzerine özellikle deprem için önemli çalışmalar yapılmıştır. $\mathrm{Bu}$ çalışmalara sırası ile, Sismoloji, Erken uyarı sistemi, CBS 'nin afet yönetiminde kullanımı, Afet Yönetimi, İletişim sistemleri, Kentsel dönüşüm, Afet algıs1, Sismik izolasyon sistemleri, Yeraltı ve yer üstü yapılar konusunda yapılmıştır. Bu çalışmada Sismoloji, Erken uyarı sistemleri CBS, Afet algısı üzerine yapılmış çalışmalar incelenmiştir. Gelecekte iletişim sistemleri, kentsel dönüşüm, sismik izolasyon sistemleri, Yeraltı ve yer üstü yapıların direnci konuları incelenecektir. Afetlere müdahale kurumları (Türk Kızılayı, AFAD ve UMKE) da uygulamada kapasitelerini artırmaktadır. Bu kurumların son depremlerde ki performansları takdire şayandır. Türk Kızılayı ve Milli Eğitim Bakanlığı ile 18 milyon öğrenciye 2018 yılında Afet Eğitim Protokolu yapmıștır. Afet eğitimi makro düzeyde medyada kamu spotları ile daima canlı tutulmalıdır. Türk Kızılayı 2018 yılında Afette gönüllü sayısını 2 milyona yükseltmeyi hedeflemektedir[31]. Türk Kızılayı 9 bölge ve 23 Yerel afet merkezi ile bir anda 320 bin kişiye sıcak yemek, 200 bin kişiye çadır dağıtabilmektedir. Unutmayalım afet öncesi afet için harcanacak 1,00 TL afet sonras1 7,00 TL harcamayı ortadan kaldıracaktır.

\section{Sonuçlar}

Marmara Bölgesinde;

Kentsel dönüşümde kat malikleri ve muhataplar arasında yeni bir model geliştirilmelidir AFAD deprem verilerini tek muhatap kurumu olarak kamuoyuna açıklamalıdır.

BİT’nin Afet yönetiminde kullanılması yaygınlaştırılmalıdır. Anlık veri kullanılmalıdır. Deprem araştırmaları için bir laboratuar kurulmalı ve yurtdışı kurumlarla iletişimi sağlanmalıdır. Marmara bölgesi için deprem master planı hazırlanmalıdır.

Afet yönetimi sistemi çalışmaları ve projeler desteklenmeli, afet bilinci artırılmalıdır. 
Yapısal olmayan elemanlar yapı ruhsatı verilirken kontrol edilmelidir.

\section{Teşekkür}

Bu çalışmada, Türk Kızılay, AFAD ve Kocaeli Büyükşehir Belediyesi Deprem ve Zemin Müdürlüğünün verileri paylaşmasından dolayı teşekkürü bir borç biliriz.

\section{Kaynaklar}

[1]Ipek, C., Kuzucuoglu, A.H., 2016."Importance of Kocaeli Earthquake Disaster Risk Reduction(DRR)"International Symposium on Natural Hazards and Hazard Management DAAYS'16, March 2-4, Karabuk University, Karabük, Turkey.

[2]Ipek, C., 2016. "Impact of Nonstructural Systems on Important Structures in Earthquake"International Symposium on Natural Hazards and Hazard Management DAAYS'16, March 2-4, Karabuk University, Karabuk, Turkey.

[3]Uckan, E., Akbas, B., Kayac, S.E., Cakır, F., Ipek, C., Makarac1, M., Ataoglu, S., 2016. "Design Issues of Buried Piplines at Permanent Ground Deformation Zones"International Symposium on Natural Hazards and Hazard Management DAAYS'16, March 2-4, Karabük University, Karabük, Turkey.

[4]Makarac1, M.,Ipek, C., 2015."Analysis of Stresses of The Buried Pipline as Results of Earthquake Effect" 5th. International Earthquake Symposium Kocaeli, Turkey.

[5]Ipek, C., Constantinou, C.M.,Tapan, M., 2015. "An Experimental Study of Viscous Damping Devices on The Behavior of Seismically Isolated Structures"5th. International Earthquake Symposium Kocaeli, Turkey.

[6]Ipek, C., 2015. "Investigation of Nonstructural Systems Under Earthquake Effect" 5th. International Earthquake Symposium Kocaeli, Turkey.

[7]Ipek, C., Kuzucuoglu, A.H., Kistır M.R., 2015."Evaluation of Nonstructural Systems in Terms of Earthquake Effects," International Burdur \& Environment Symposium(IBEES2015),Burdur, Turkey.

[8]Ambraseys, N. N., FinkelC. F., 1991. "Long-term seismicity of Istanbul and of the Marmara Searegion", Terra Nova, 3, pp: 527-539

[9] Ambraseys, N. N., Finkel C. F., 1995. The seismicity of Turkey and adjacent areas: A historicalreview, Istanbul: Muhittin Salih Eren.

[10]Akyuz, H. S., Barka A., Altunel E., Hartleb R., Sunal G., 2000."Field Observations and SlipDistribution of the November 12, 1999 DüzceEarthquake (M=7.1), Bolu-Turkey", The 1999 Izmit and Düzce Earthquakes: Preliminary Results, Istanbul Tech. Un. Press, Istanbul, pp. 61-70 [11]Yaltirak, C.,2002."Tectonic evoluation of Marmara Sea and its surroundings", Marine Geology, pp.1-37

[12]Durukal, E., Cimilli, S., Erdik, M.,2003."Dynamic response of two historical monuments in Istanbuldeduced from the recordings of Kocaeli and Duzce earthquakes",Bulletin of SeismologicalSociety of America, 93 (2): pp. 694-712

[13]Parsons, T., TodaS., SteinR.S., Barka A.A., DieterichJ. H., 2000. " Heightened odds of large earthquakes near Istanbul: An interaction-based probability calculation"Science, 288, pp.661-665 [14]Ambraseys, N. N., JacksonA., 2000. "Seismicity of the Sea of Marmara (Turkey) Since 1500",Geophys. J. Int., 141, F1-F6 
[15]Smyth,A.W.,et al., 2004."Probabilistic Benefit-Cost Analysis for Earthquake Damage Mitigation:Evaluating Measures for ApartmentHouses in Turkey"Earthquake Spectra,20(1), pp. $171-203$

[16]Erdik, M., Demircioglu, M., Sesetyan, K., Durukal, E., Siyahi, B., 2004. "Earthquake Hazard in Marmara Region, Turkey"13th World Conference on Earthquake Engineering Vancouver, B.C., CanadaAugust 1-6,Paper No:270

[17]Akkar, S., Gulkan, P., 2002. "A critical examination of near-field accelerograms from the Sea of Marmara region earthquakes", Bull. Seismol. Soc. Am.92, pp.428-447.

[18]"Açıklamalı Afet Yönetimi Terimleri Sözlüğü", 2014. AFAD, Ankara.

[19]Alçık, H. A., 2011. "Deprem Erken Uyarı Sistemleri" Van Depremi ve Deprem Özel Sayısı, 2011 Jeofizik Bülteni, Jeofizik Mühendisleri Odas1, Ankara.

[20]Gündoğdu, O.,Işık, Ö., Uzel, T., Ürüşan, A. Y., Agalday, F., 2017."Afet Yönetiminde Erken Uyarı Sisteminin Önemi"4. Uluslararası Deprem Mühendisliği ve Sismoloji Konferans1 11-13 Ekim, Anadolu Üniversitesi, Eskişehir, Turkey

[21]Demirci, A., Karakuyu, M.,2004. "Afet Yönetiminde Coğrafi Bilgi Teknolojilerinin Rolü" Doğu Coğrafya Dergisi 12. pp:67-100

[22]Ilter, H.B., Özkeser, İ., 2012."Coğrafik Bilgi Sistemleri ile Afet ve Acil Durum Yönetim Bilgi Sistemeleri"TMMOB Afet Sempozyumu

[23]Güven,İ. T., 2017. "A Geographic Information System Designed for Disaster Management"4.

Uluslararası Deprem Mühendisliği ve Sismoloji Konferansı 11-13 Ekim, Anadolu Üniversitesi, Eskişehir, Turkey.

[24]Kundak, S., Türkoğlu H., İlki A., 2014."Risk perception in Istanbul: An earthquake-prone city",ITU A|Z, 11(1), pp. 117-137

[25]Fişek, G.O., Yeniceri, N., Muderrisoglu, S., 2002."Risk Perception and Attitudes Towards

Mitigation", IIASA-DPRI Meeting, July 29-31 2002 Laxenburg Austria.

[26]Ahrazoğlu A., Bikce M., 2017. "Kentesel Dönüşümün Yap1 Maliyetine Etkisinin İncelenmesi" 4. Uluslararası Deprem Mühendisliği ve Sismoloji Konferans1 11-13 Ekim 2017, Anadolu Üniversitesi, Eskişehir

[27]Ipek ,C., ve Dikici M. 2018."Evaluation of Disaster Studies in Marmara Region " 2nd International Symposium on Natural Hazards and Disaster Management 04-06 May (ISHAD2018 Sakarya Turkey)

[28]Usta H.T., Ulger N.E., IBAN C., 2015. " Urban Regeneration in Istanbul ; Gaziosmanpaşa Case " FIG Working Week, 17-21 May Sofia ,Bulgaria

[29]TRT Haber Gece Bakış1 2018. "https://www.youtube.com/watch?v=22TmKsrD ts" , Özel canlı yayın programı,Gölcük, Kocaeli

[30]Zülfikar., A.C., 2018." Afet Zararların Azaltılmasında Akıllı kent Uygulamaları",V. Uluslararası Deprem Gerçeği ve Kentleşme Çalıştayı, 16 Ağustos 2018, İzmit,Kocaeli

[31]Ipek. C ., 2018."Afetlerde Kızılayın Rolü",V. Uluslararası Deprem Gerçeği ve Kentleşme Çalıştayı,16 Ağustos 2018, İzmit,Kocaeli

[32]Tarhan Ç., Aydın C., 2017. "Bilişim Sistemleri Kullanılarak Afet Direnci Artırılabilir mi? " 4. Uluslararası Deprem Mühendisliği ve Sismoloji Konferansı 11-13 Ekim 2017,Anadolu Üniversitesi, Eskişehir

[33]Ozmen B., Pampal S., 2017. "Türkiye Deprem Haritalarının Evrimi" 4. Uluslararası Deprem Mühendisliği ve Sismoloji Konferansı 11-13 Ekim 2017, Anadolu Üniversitesi, Eskişehir 